\title{
Microstructural and Surface Texture Analysis due to Machining in Super Austenitic Stainless Steel
}

\author{
Mohanad Alabdullah, A. Polishetty, and G. Littlefair \\ School of Engineering, Deakin University, Waurn Ponds, VIC 3216, Australia \\ Correspondence should be addressed to A. Polishetty; ashwin.polishetty@deakin.edu.au
}

Received 6 June 2016; Revised 24 August 2016; Accepted 4 September 2016

Academic Editor: Elena V. Pereloma

Copyright (C) 2016 Mohanad Alabdullah et al. This is an open access article distributed under the Creative Commons Attribution License, which permits unrestricted use, distribution, and reproduction in any medium, provided the original work is properly cited.

Inferior surface quality is a significant problem faced by machinist. The purpose of this study is to present a surface texture analysis undertaken as part of machinability assessment of Super Austenitic Stainless Steel alloy-AL6XN. The surface texture analysis includes measuring the surface roughness and investigating the microstructural behaviour of the machined surfaces. Eight milling trials were conducted using combination of cutting parameters under wet machining. An optical profilometer (noncontact) was used to evaluate the surface texture at three positions. The surface texture was represented using the parameter, average surface roughness. Scanning Electron Microscope was utilised to inspect the machined surface microstructure and correlate the microstructure with the surface roughness. Results showed that maximum roughness values recorded at the three positions in the longitudinal direction (perpendicular to the machining grooves) were $1.21 \mu \mathrm{m}$ (trial 1), $1.63 \mu \mathrm{m}$ (trial 6), and 1.68 $\mu \mathrm{m}$ (trial 7), respectively, whereas the roughness values were greatly reduced in the lateral direction. Also, results showed that the feed rate parameter significantly influences the roughness values compared to the other cutting parameters. The microstructure of the machined surfaces was distorted by the existence of cracks, deformed edges, and bands and wear deposition due to machining process.

\section{Introduction}

Surface texture as a result of machining process is of great importance which needs to be considered before using the machined part in a design application [1]. One of the major problems of machining austenite stainless steel (ASS) is the quality of the machined surface. Therefore, an in-depth investigation of factors leading to surface texture deterioration due to machining is required. Workpiece physical properties, the cutting tool geometry and the applied cutting speed, and feed rate and depth of cut are some of the factors that alter the roughness of the machined surface [2]. Recently, the authors of this work conducted a preliminary machining study to assess the machinability of the AL6XN SASS alloy relating to the cutting forces, surface microhardness, and surface roughness [3]. Their study showed that the applied cutting parameters significantly influenced the surface roughness values which in turn affected the cutting forces and the surface microhardness values. As the conducted paper included a preliminary study, the surface roughness values were calculated at randomly selected spots on the machined bays. Therefore, this work aims to investigate the effects of the cutting parameters and the microstructural behaviour of the machined surfaces on the surface texture at various selected spots according to the preceding of the machining process. Daud et al. optimized the machinability of the stainless steel and brass workpieces. Their research aim was to find the optimum surface finish when combinations of cutting parameters were applied using milling. The outcomes show an improved surface quality when high spindle speed was used whereas the roughness values remain constant at low feed rate [4]. Berkani et al. explained the relation between the surface roughness and the cutting parameters with respect to the cutting time. Researchers machined a bar of workpiece made of AISI 304 stainless steel under coated inserts using turning machine. The roughness values were significantly influenced by the cutting time, the feed rate, and finally the cutting speed. Rougher surfaces were obtained for long cutting time due to generated wear, high feed, and cutting speed [5]. Austenitic stainless steel type 1Cr18Ni9Ti was cut 
using ceramic cutting tool on a turning machine to establish the produced surface roughness [6]. Multiple cutting trials were performed using combinations of cutting parameters to inspect the impacts of the main cutting parameters on the machinability process. The feed rate had the highest rank compared with the applied depth of cut in deteriorating the roughness values. Ciftci evaluated the surface roughness throughout the dry machining of AISA 316 and AISI 304 austenite stainless steel and concluded that the roughness values for both alloys were low when the cutting speed was elevated to a certain limit. A high tendency to form the BUE and wear on the edges of the cutting tool at a slow cutting speed deteriorated the machined surface [7]. Xavior and Adithan studied the effects of the applied coolant on the quality of the machined surface during turning of austenite stainless steel. The outcomes revealed that using low feed rate during machining improved the quality of the machined surfaces [8]. Selvaraj and Chandramohan examined the gained roughness values during machining process regarding the cutting speed, feed, and depth of cut [9]. Machinability of AISI 316 austenite stainless steel was studied by Çiçek et al. The alloy was drilled without coolant. The effects of the spindle speed and the feed rate were estimated. The cutting speed had a major effect on the surface roughness value by up to $78 \%$ [10].

As mentioned earlier in the literature, the purpose of this work is to compensate the lack of information on the prediction of the surface roughness values when Super Austenitic Stainless Steel (SASS) is machined. To the best of our knowledge, machinability assessment of AL6XN SASS alloy due to surface texture analysis using an optical profilometer and Scanning Electron Microscope (SEM) has not been studied in machining field. Therefore, this paper aim is to evaluate and analyse the surface roughness and the microstructure of the machined surfaces relating to the cutting parameters when SASS alloy-AL6XN is machined. Alicona Infinite Focus (AIF) 3D optical profilometer considered a new technique to evaluate the surface roughness, which was used in this research. The Alicona profilometer is a noncontact imager instrument measuring the roughness based on a focus variation process. The benefit of using an optical imager is measuring the roughness values precisely without causing any surface damage compared to the conventional contact measurements. Studies have been conducted on predicting the surface roughness values during machining of various materials using noncontact and contact instruments and the results confirmed that accurate roughness values were gained when the noncontact measurements were executed [11-13]. The outputs from this paper can be applied as a pretest condition by a machinery manufacturer. This helps to improve the machinist awareness about selecting the cutting parameters as well as the cutting direction to minimise the surface roughness to a certain extent.

\section{Materials and Methods}

The chemical composition of the AL6XN alloy has been evaluated using spectrometry test. This test was performed by SPECTROMAXx instrument. The procedure used for the
TABLE 1: AL6XN SASS chemical composition.

\begin{tabular}{ccccccccc}
\hline & \multicolumn{8}{c}{ Element } \\
& $\mathrm{C}$ & $\mathrm{Mn}$ & $\mathrm{P}$ & $\mathrm{Mo}$ & $\mathrm{Cr}$ & $\mathrm{Ni}$ & $\mathrm{S}$ & $\mathrm{Si}$ \\
\hline Weight (\%) & 0.026 & 0.370 & 0.044 & 6.066 & 21 & 24 & 0.002 & 0.360 \\
\hline
\end{tabular}

TABLE 2: Parameters of conducted experiments.

\begin{tabular}{lcccc}
\hline Trial & $\begin{array}{c}\text { Feed rate } f \\
(\mathrm{~mm} / \text { tooth })\end{array}$ & $\begin{array}{c}\text { Cutting depth } d \\
(\mathrm{~mm})\end{array}$ & $\begin{array}{c}\text { Cutting speed } \\
V_{c}(\mathrm{~m} / \mathrm{min})\end{array}$ & Coolant \\
\hline 1 & 0.1 & 2 & 100 & \\
2 & 0.1 & 3 & 100 & \\
3 & 0.15 & 2 & 100 & \\
4 & 0.15 & 3 & 100 & On \\
5 & 0.1 & 2 & 150 & \\
6 & 0.1 & 3 & 150 & \\
7 & 0.15 & 2 & 150 & \\
8 & 0.15 & 3 & 150 & \\
\hline
\end{tabular}

spectrometry test was an Optical Emission Spectrometry (OES) that depends on the intensity of the emitted radiation. During the test, small piece of the sample was vaporised by applying an arc spark discharge. The vapour included the ions and atoms of the elements within the alloy microstructure. These elements have emitted wavelengths of different intensity. These wavelengths were measured and compared to the preserved database to calculate the chemical composition of the tested material as a percent concentration. The elements present in the currently used workpiece are itemised in Table 1.

A total of 8 milling trials were executed under a combination of cutting parameters which included cutting speeds $V_{c}$ of 100 and $150 \mathrm{~m} / \mathrm{min}$; feed rates $f$ of 0.1 and $0.15 \mathrm{~mm} /$ tooth; and depth of cuts $d$ of 2 and $3 \mathrm{~mm}$. These cutting conditions as well as the optical profilometer settings used to observe the results were selected based on a recently published study by the authors on machinability of AL6XN SASS [3]. Coolant made of phenol-water mixture $(1: 10)$ was applied during machining. The coolant port was subjected on the cutting tool tip to supply the workpiece-cutting tool contact area (shear zone) with the flood coolant during the cutting process. Table 2 lists the arrangements of the parameters of conducted experiments used for the cutting process.

Machining trials were conducted on 5-axis $\mathrm{CNC}$ milling machine (SPINNER U620) having specification of spindle power, $15 \mathrm{~kW}$, and a table diameter of $650 \mathrm{~mm}$. Insert type cutting tool-ISCAR HELIDO 490-09, TiCN, TiN coated inserts were used for the trials. The cutting tool holder was designed to clamp two cutting inserts. Each cutting insert has four cutting edges of $0.8 \mathrm{~mm}$ radius per edge. Each cutting trial was machined under a new cutting edge in order to maintain a constant reference (zero) tool wear condition. The workpiece of a rectangular block configuration having dimensions of $150 \mathrm{~mm}$ width and $200 \mathrm{~mm}$ length was fixed on the milling dynamometer as shown in Figure 1.

The cutting process generated eight machined bays as shown in Figure 2. The yellow arrows in Figure 2 refer to the 


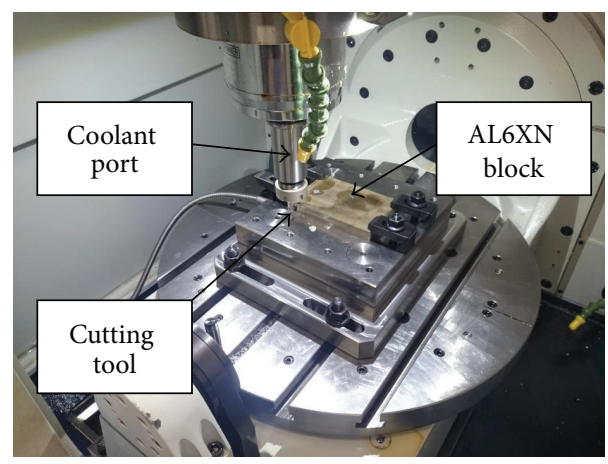

Figure 1: Experimental setup.

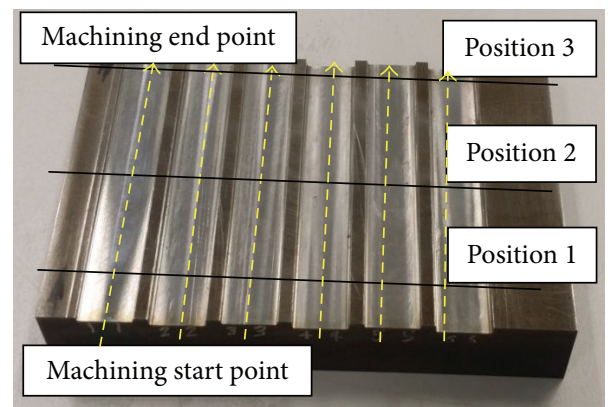

FIGURE 2: Three positions to read the surface roughness values along the machined bays.

direction of the cutting for each trial. Samples were extracted from each bay and from the three selected positions (start, middle, and end of machining). These samples were cleaned, dried, and decontaminated under vacuum in order to be inspected under the lens of the AIF and the SEM detector.

\subsection{Surface Roughness Measurement Using Alicona Infinite} Focus. Alicona Infinite Focus (AIF) is used to evaluate the surface roughness measurements of the machined parts, the profile, the form, and the wear of the cutting tools in a 3D and $2 \mathrm{D}$ view. The instrument consists of three main parts: monitor, scanning area, and the controlling joystick. The monitor displays the controlling panel which includes brightness, contrast, and the postprocessing controlling elements. The scanning area consists of the column that carries the microlens and the stage that supports and settles the sample to avoid any accidental movements. The machined samples were mounted on the stage and scanned by the optical lens of the profilometer as shown in Figure 3. Roughness measurements were then executed on the scanned machined surfaces. All the readings were recorded in two directions (Figures 3(a) and 3(b)): longitudinal (perpendicular to the machined grooves) and lateral (parallel to the machined grooves). Figure 3(a) shows the line path used to evaluate the roughness values which was drawn in a perpendicular direction to the lines of the machining grooves whereas the right image shows the line path in parallel direction to the machining grooves. Indeed, the line path is drawn (along and across the machining lines) to measure the depth and width of the machining grooves using focus variation property of the AIF instrument. When the line path crossed the machining grooves of the machined surface, the grooves depth will be calculated as a function of the path length as shown in Figure 3(c).

\subsection{Surface Roughness Inspections Using Scanning Electron} Microscope. A Zeiss Supra 55VP Electron Microscope was used to inspect the surface microstructure of the machined alloy. The applied electron microscope settings were $20 \mathrm{kV}$ acceleration voltage, $10 \mathrm{~mm}$ working distance, high current mode (on), and $60 \mu \mathrm{m}$ aperture size. Also, the specimen chamber was vacuumed at high pressure and kept in this vacuum mode during the scanning process in order to prevent the electron beam scattering when the surfaces were scanned using a Secondary Electron (SE) detector. Minor cracks and distorted and deformed zones were identified on the machined surfaces.

\section{Results and Discussion}

3.1. Surface Roughness Measurement Using Alicona Infinite Focus 3D Optical Profilometer. When the scanning process was finished, the machined surfaces were extracted and viewed as 3D and 2D surfaces as shown in Figures 4(a) and 4(b).

The $3 \mathrm{D}$ and $2 \mathrm{D}$ surface representations enable the user to observe the machining grooves distribution, depths, and directions so that the roughness measurements could be executed in various directions relating to the machining lines as shown in Figures 4(a) and 4(b). In order to ensure repeatability, the evaluation was conducted 3 times and average reading was considered.

All the gathered results were analysed and plotted in graphs as shown in Figure 5. From Figure 5(a) and position 1 for longitudinal direction, trial 8 had the highest roughness value of $1.21 \mu \mathrm{m}$, whereas the lowest roughness was obtained for trial 6 . Trials 6 and 8 had the same $V_{c}$ and $d$ but differed in $f$. High $f$ used in trial 8 was the reason for the roughness increase. The roughness value in trial 8 remained almost constant when the tool moved to position 2. From Figure 5(c) and position 2 for longitudinal direction, the roughness was elevated to $1.63 \mu \mathrm{m}$ in trial 1 which is the maximum value, while trail 6 had the lowest roughness value. In trial 1, low cutting conditions used to machine the alloy may provide sufficient time to create and spread wear on the cutting tool and thereby increase the temperature in the tool-workpiece contacting zones. These factors facilitate the deterioration of the machined surfaces.

The roughness values were increased in position 3 for all the cutting trials as shown in Figure 5(e). The maximum roughness value was obtained for position 3 , longitudinal direction, equal to $1.68 \mu \mathrm{m}$ in trial 7 as displayed in Figure 5(e). The minimum roughness value was gained in trial 2 where the low speed and $f$ were applied. As the AL6XN SASS alloy is a ductile material, the temperature can be easily elevated in the tool-workpiece contact area which forms wear and BUE on the cutting insert. The wear and BUE are main factors in deteriorating the roughness of the machined parts as reported by Oliaei and Karpat [14]. 


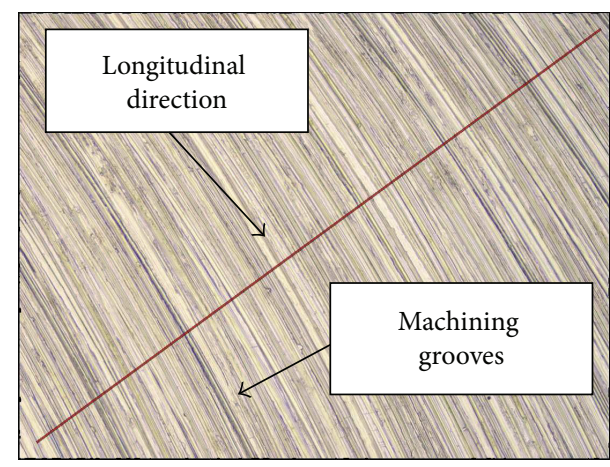

(a)

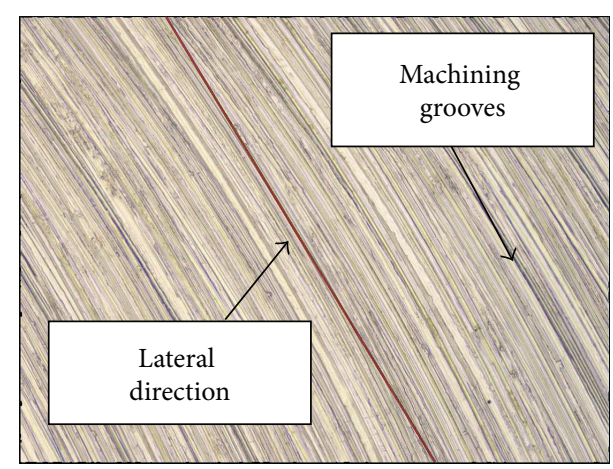

(b)

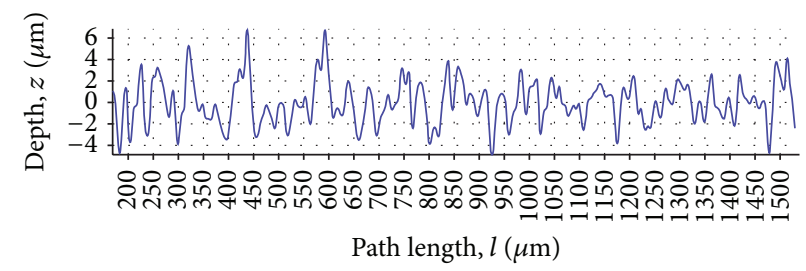

(c)

FIGURE 3: Roughness measurement direction. (a) Longitudinal. (b) Lateral. (c) Graphical representation for the path length and the groove depth (roughness values) in $\mu \mathrm{m}$.

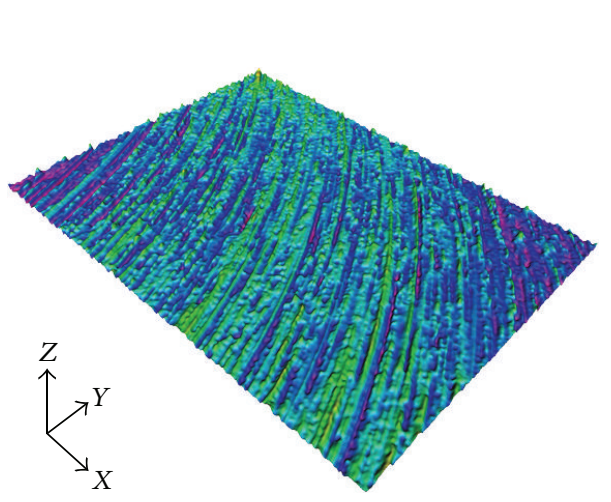

(a)
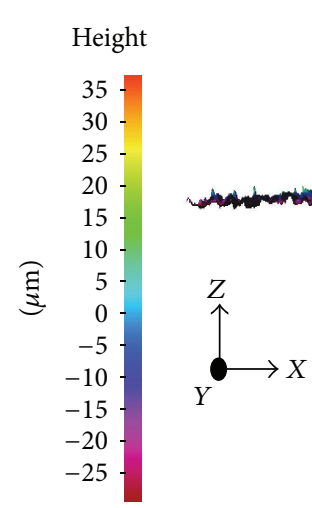

(b)

FIGURE 4: Representation of the scanned machined surface by the AIF optical lens. (a) 3D view. (b) 2D view.

It can be concluded that the $f$ parameter significantly influenced the roughness values during machining process and this is also evident by Fnides and Yallese [15]. The relation in Table 3 can be concluded from presented roughness graphs in Figures 5(a), 5(b), and 5(e) (longitudinal graphs).

In Table 3, the roughness Ra was inversely proportional to the $f$ values for positions 1 and 2 when $100 \mathrm{~m} / \mathrm{min}$ and $150 \mathrm{~m} / \mathrm{min} V_{c}$ and $2 \mathrm{~mm} d$ were applied whereas the roughness $\mathrm{Ra}$ was directly proportional to $f$ when $3 \mathrm{~mm} d$ was used with the same $V_{c}$. For position 3 , the roughness Ra was inversely proportional to $f$ when $100 \mathrm{~m} / \mathrm{min} V_{c}$ and $2 \mathrm{~mm} d$ were used whereas at $150 \mathrm{~m} / \mathrm{min} V_{c}$ and $3 \mathrm{~mm} d$ the roughness Ra was directly proportional to the $f$ value.

In general, the examined machined surfaces had significantly low roughness values in the lateral direction as
TABLE 3: Changes in roughness Ra relating to the applied cutting parameters at positions 1,2 , and 3 .

\begin{tabular}{lcc}
\hline Position & $\begin{array}{c}\text { Changes in roughness Ra relating to the cutting } \\
\text { parameters }\end{array}$ \\
\hline \multirow{2}{*}{ and 2} & For 100 and $150 \mathrm{~m} / \mathrm{min}$ & $\mathrm{Ra} \propto 1 / f$ at low depth of cut \\
& $V_{c}$ & $\mathrm{Ra} \propto f$ at high depth of cut \\
\hline \multirow{2}{*}{3} & For $100 \mathrm{~m} / \mathrm{min} V_{c}$ & $\mathrm{Ra} \propto 1 / f$ at low depth of cut \\
& For $150 \mathrm{~m} / \mathrm{min} V_{c}$ & $\mathrm{Ra} \propto f$ at high depth of cut \\
\hline
\end{tabular}

shown in Figures 5(b), 5(d), and 5(f) compared to the roughness values obtained in the longitudinal direction. However, this comparison helps to improve the machinist awareness before manufacturing the machined parts used for 


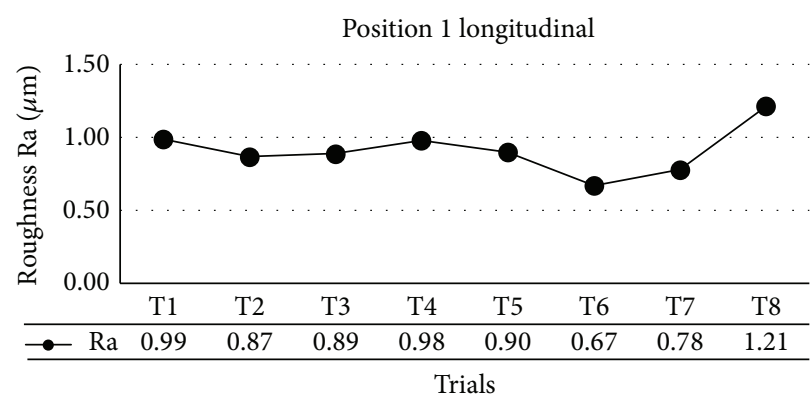

(a)

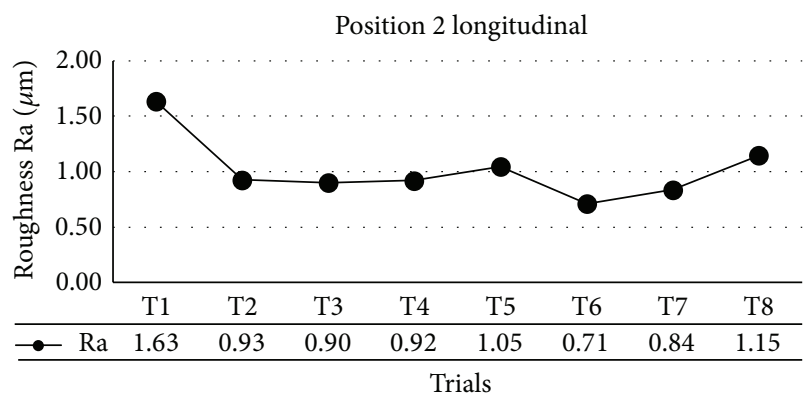

(c)

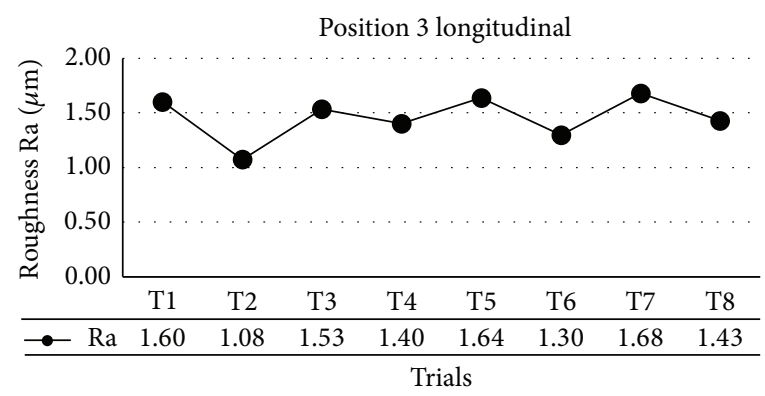

(e)

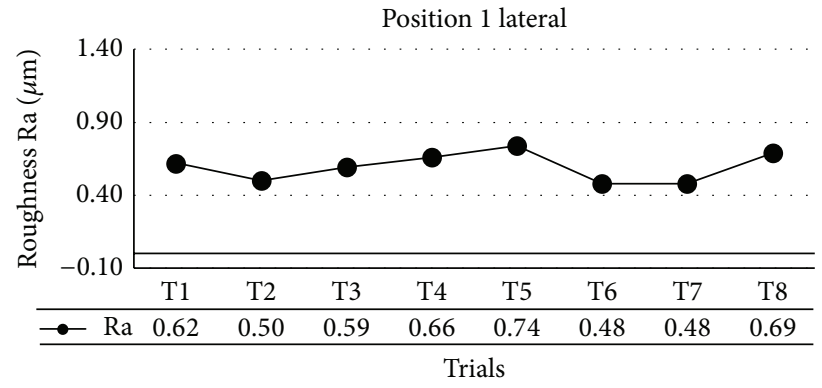

(b)

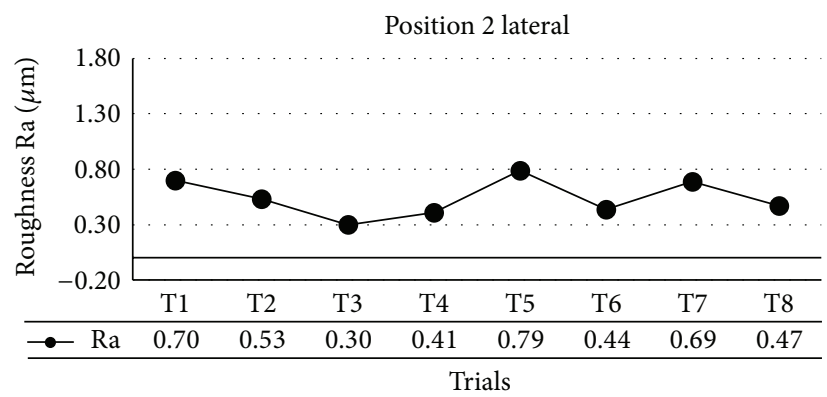

(d)

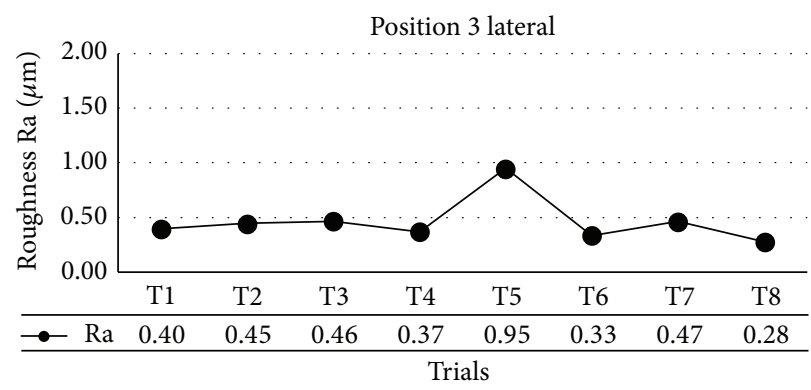

(f)

FIgURE 5: Roughness Ra $(\mu \mathrm{m})$ measured in positions 1-3. (a) Longitudinal Ra values of the 8 cutting trials at position 1. (b) Lateral Ra values of the 8 cutting trials at position 1. (c) Longitudinal Ra values of the 8 cutting trials at position 2. (d) Lateral Ra values of the 8 cutting trials at position 2. (e) Longitudinal Ra values of the 8 cutting trials at position 3. (f) Lateral Ra values of the 8 cutting trials at position 3.

tough applications where high friction between the contacted surfaces is found, for example, the friction between the teeth of two contacted gears, and the high roughness values (undesirable) are expected. These machined parts should be manufactured in a direction (feed direction) parallel as much as possible to their working direction in industry to minimise the undesirable roughness to its lowest values.

3.2. Microstructural Inspection of the Microstructure of the Machined Surfaces Using SEM. The machined surfaces were inspected under the SEM detector to reveal the surface distortions created in the microstructure. Due to resource limitations, only four samples $(1,4,5$, and 8$)$ were selected and presented in Figures 6 and 7.

For each sample, three images were captured to present the three mentioned positions. An appropriate surface finish with a small number of minor cracks was produced in trial 1 position 1 (Figure 6(a)). Furthermore, a good surface finish at position 2 (Figure 6(c)) was accomplished whereas at position
3 (Figure 6(e)), minor cracks increased and few distorted areas and bands were noticed.

From Figure 6(b), trial 4 position 1, the machined surfaces show cracks and distortions. It can be seen that a few minor cracks were found and poor surface finish with low distortions was accomplished. For trial 4 position 2 (Figure $6(\mathrm{~d})$ ), the crack size increased as well as distortion in sizes and numbers. The distortions were arranged in parallel bands which have a size range of $12.5-25 \mu \mathrm{m}$. For trial 4 position 3 (Figure 6(f)), the distortion sizes increased up to $62 \mu \mathrm{m}$ in some areas. Effects of the BUE and chipping wear deposit remarkably lead to large distortions, as reported by Zhou et al. [16], of $196 \mu \mathrm{m}$ in size above the machined surface and cause the roughness values to increase.

Machined surface of trail 5 position 1 (Figure 7(a)) shows slightly deformed spots and bands whereas the distorted bands increased in position 2 (Figure $7(\mathrm{c})$ ). The width of the distorted bands in position 2 increased up to $23 \mu \mathrm{m}$ and some noticeable deformed edges were created. Deep distorted 


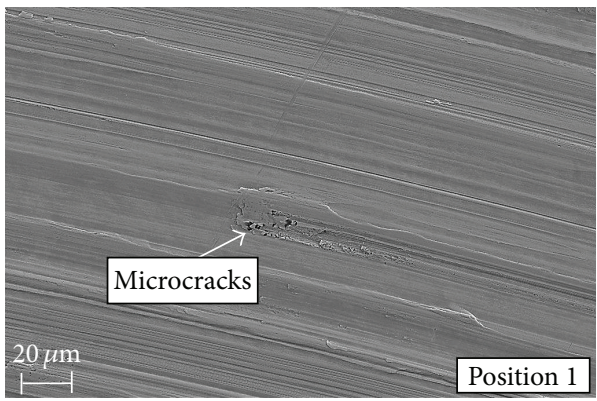

(a)

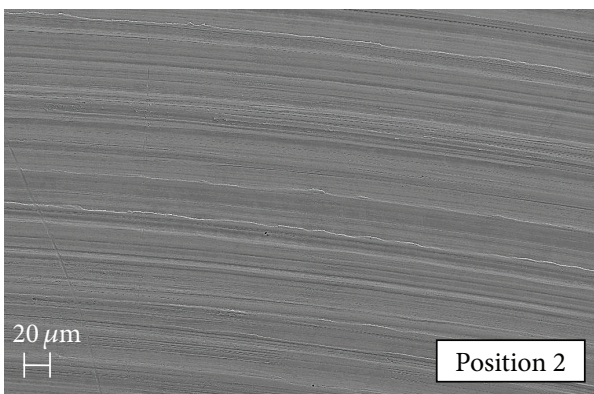

(c)

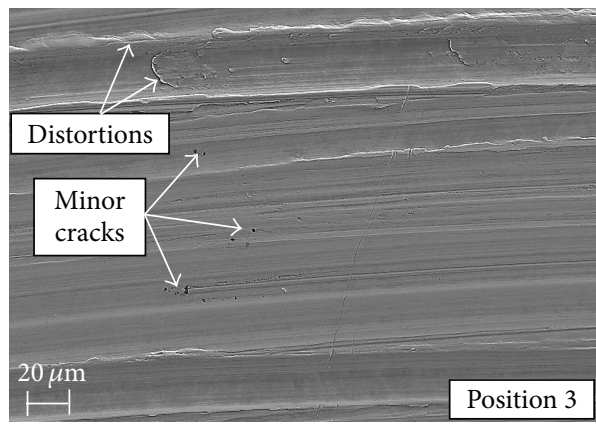

(e)

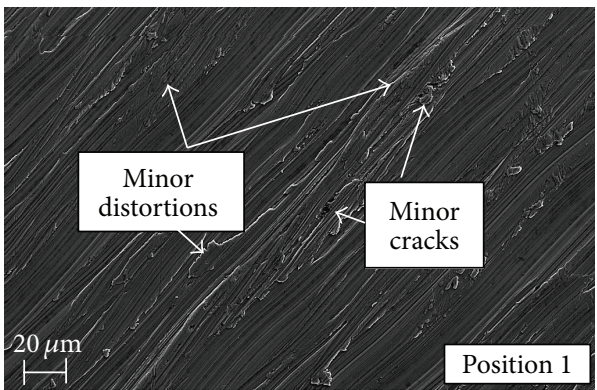

(b)

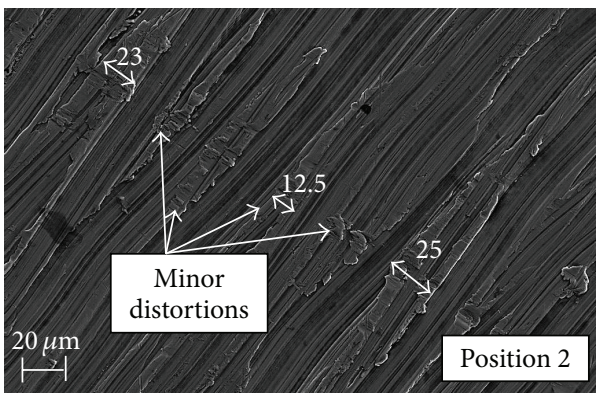

(d)

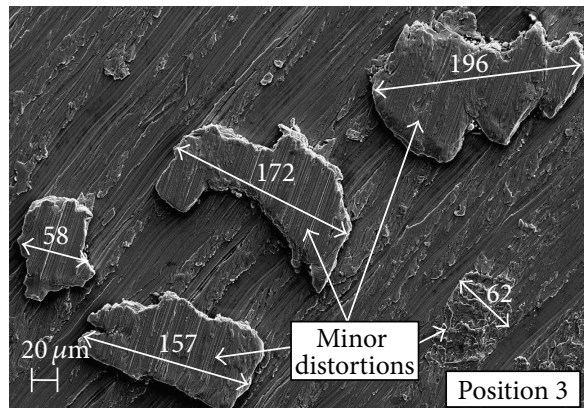

(f)

Figure 6: Distortion analysis for the microstructure of the machined surfaces of trials 1 and 4 using SEM. (a) Trial 1 at position 1 . (b) Trial 4 at position 1. (c) Trial 1 at position 2. (d) Trial 4 at position 2. (e) Trial 1 at position 3. (f) Trial 4 at position 3.

bands were formed at position 3 (Figure 7(e)). Also, deformed areas appeared above the machining grooves.

The machined surface of trial 8 is displayed in Figures 7(b), 7(d), and 7(f). At position 1, minor cracks and distortion spots appeared. However, the distorted spot increased in size and also in occurrence, which can be easily recognized. The width of the largest distorted band was recorded and equals width of $15.3 \mu \mathrm{m}$. Position 3 reveals that the width in some distorted bands increased up to $16.5 \mu \mathrm{m}$. In addition, deformed edges were strongly created between the machining grooves. Also, significant distortions existed above the machined surface and triggered the roughness values to increase.

Most of the minor and medium distortions found on the machined surfaces in Figures 6(b), 6(d), and 6(e) and Figures 7(b), 7(d), and 7(f) present the material plastic flow. This plastic flow can be related to the elevated temperature in the shear zone during the cutting process and the material ductility nature significantly affected by the wear of the cutting insert and instance coolant condition [16].

\section{Conclusions}

The machined surfaces of the AL6XN Super Austenitic Stainless Steel were subjected to surface texture and microstructural analysis using an optical profilometer and SEM, respectively. The following results were obtained:

(1) At position 1, a maximum roughness value of $1.21 \mu \mathrm{m}$ was noticed in trial 8 . At the middle position, the roughness value of trial 1 increased to the maximum value of $1.63 \mu \mathrm{m}$. At the end of the cutting process, the maximum roughness value of $1.68 \mu \mathrm{m}$ was observed in trial 7.

(2) The roughness values of the eight cutting trials reduced to minimum values once the measurements 


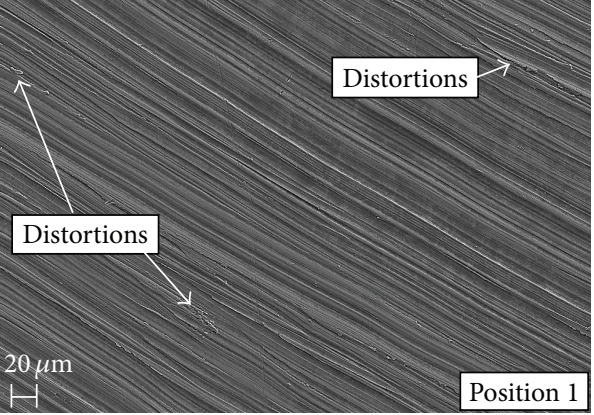

(a)

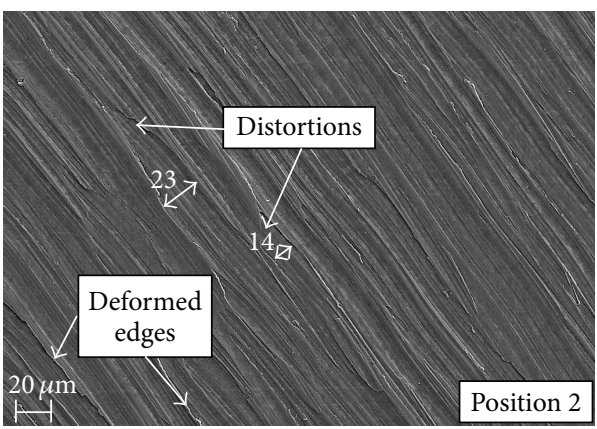

(c)

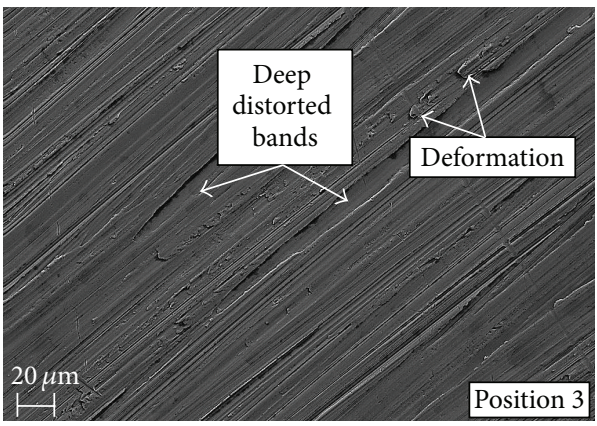

(e)

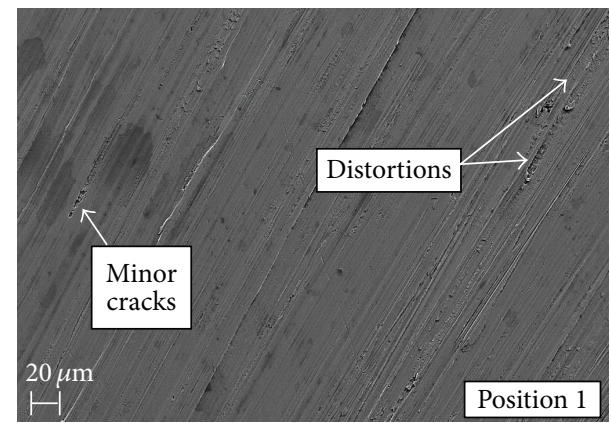

(b)

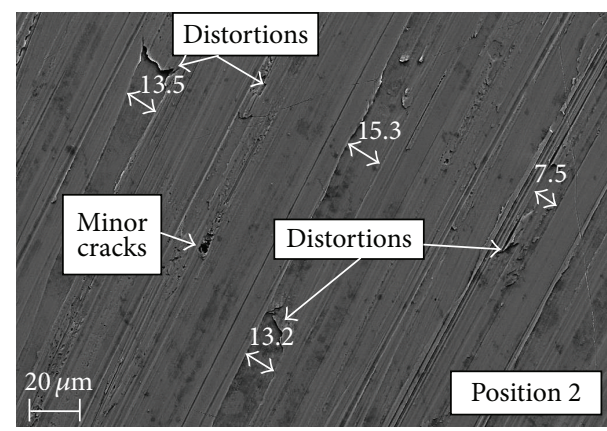

(d)

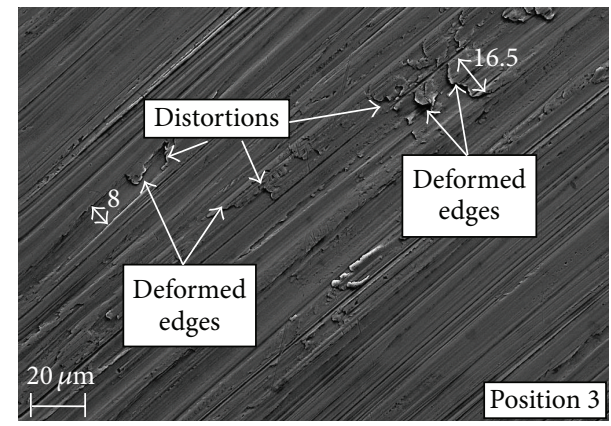

(f)

Figure 7: Distortion analysis for the microstructure of the machined surfaces of trials 5 and 8 using SEM. (a) Trial 5 at position 1 . (b) Trial 8 at position 1. (c) Trial 5 at position 2. (d) Trial 8 at position 2. (e) Trial 5 at position 3. (f) Trial 8 at position 3.

were executed in the lateral direction (parallel to the machined grooves).

(3) The roughness $\mathrm{Ra}$ of the machined surfaces were significantly influenced by the feed rate followed by the cutting speed and then by the depth of cut. The Ra value was directly and inversely proportional to the feed rate values depending on the applied cutting speed and the location along the machining grooves where the roughness measurements were recorded.

(4) The rougher surfaces showed the existence of minor cracks, distorted areas, deformed edges, and bands as well as a plastic flow behaviour when the surfaces were examined under a SEM detector. The size and number of cracks and distortions varied with respect to the applied cutting parameters.

\section{Competing Interests}

The authors declare that they have no competing interests.

\section{References}

[1] P. G. Benardos and G.-C. Vosniakos, "Predicting surface roughness in machining: a review," International Journal of Machine Tools and Manufacture, vol. 43, no. 8, pp. 833-844, 2003.

[2] D. Umbrello, G. Ambrogio, L. Filice, and R. Shivpuri, "A hybrid finite element method-artificial neural network approach for predicting residual stresses and the optimal cutting conditions during hard turning of AISI 52100 bearing steel," Materials \& Design, vol. 29, no. 4, pp. 873-883, 2008.

[3] A. Polishetty, M. F. A. Alabdullah, N. Pillay, and G. Littlefair, "A preliminary study on machinability of super austenitic stainless steel," in Proceedings of the ASME International Mechanical 
Engineering Congress and Exposition, Paper no. IMECE201550224, American Society of Mechanical Engineers, Houston, Tex, USA, November 2015.

[4] M. Daud, W. T. Ng, D. L. Sivakumar, and M. Z. Selamat, "The evaluation of machinability and surface roughness in conventional vertical milling machine," in Proceedings of the Proceedings of Mechanical Engineering Research Day (MERD '15), pp. 133-134, Centre for Advanced Research on Energy, March 2015.

[5] S. Berkani, L. Bouzid, H. Bensouilah, M. A. Yallese, F. Girardin, and T. Mabrouki, "Modeling and optimization of tool wear and surface roughness in turning of austenitic stainless steel using response surface methodology," in Proceedings of the 22ème Congrès Français de Mécanique, Lyon, France, 2015, http://hdl.handle.net/2042/57603.

[6] Z. Yin, C. Huang, J. Yuan, B. Zou, H. Liu, and H. Zhu, "Cutting performance and life prediction of an $\mathrm{Al}_{2} \mathrm{O}_{3} / \mathrm{TiC}$ micro-nanocomposite ceramic tool when machining austenitic stainless steel," Ceramics International, vol. 41, no. 5, pp. 7059-7065, 2015.

[7] I. Ciftci, "Machining of austenitic stainless steels using CVD multi-layer coated cemented carbide tools," Tribology International, vol. 39, no. 6, pp. 565-569, 2006.

[8] M. A. Xavior and M. Adithan, "Determining the influence of cutting fluids on tool wear and surface roughness during turning of AISI 304 austenitic stainless steel," Journal of Materials Processing Technology, vol. 209, no. 2, pp. 900-909, 2009.

[9] D. P. Selvaraj and P. Chandramohan, "Optimization of surface roughness of AISI 304 austenitic stainless steel in dry turning operation using Taguchi design method," Journal of Engineering Science and Technology, vol. 5, no. 3, pp. 293-301, 2010.

[10] A. Çiçek, T. Kıvak, and G. Samtaş, "Application of taguchi method for surface roughness and roundness error in drilling of AISI 316 stainless steel," Strojniški Vestnik/Journal of Mechanical Engineering, vol. 58, no. 3, pp. 165-174, 2012.

[11] E. Koçer, E. Horozolu, and I. Asiltürk, "Noncontact surface roughness measurement using a vision system," in Proceedings of the 7th International Conference on Machine Vision (ICMV '14), vol. 9445 of Proceedings of SPIE, November 2014.

[12] S.-B. Liu and H.-F. Yu, "Surface roughness measurement by image processing method," in Proceedings of the Measurement Technology and Intelligent Instruments, vol. 1323 of Proceedings of SPIE, Wuhan, China, October 2003.

[13] C. Y. Poon and B. Bhushan, "Macro and micro-tribology and mechanics of magnetic storage systems comparison of surface roughness measurements by stylus profiler, AFM and noncontact optical profiler," Wear, vol. 190, no. 1, pp. 76-88, 1995.

[14] S. N. B. Oliaei and Y. Karpat, "Investigating the influence of built-up edge on forces and surface roughness in micro scale orthogonal machining of titanium alloy Ti6Al4V," Journal of Materials Processing Technology, vol. 235, pp. 28-40, 2016.

[15] B. Fnides and M. Yallese, "Cutting forces and surface roughness in hard turning of hot work steel X38CrMoV5-1 using mixed ceramic," Mechanics, vol. 70, no. 2, pp. 73-78, 2016.

[16] J. Zhou, V. Bushlya, P. Avdovic, and J. E. Ståhl, "Study of surface quality in high speed turning of Inconel 718 with uncoated and coated CBN tools," The International Journal of Advanced Manufacturing Technology, vol. 58, no. 1-4, pp. 141-151, 2012. 

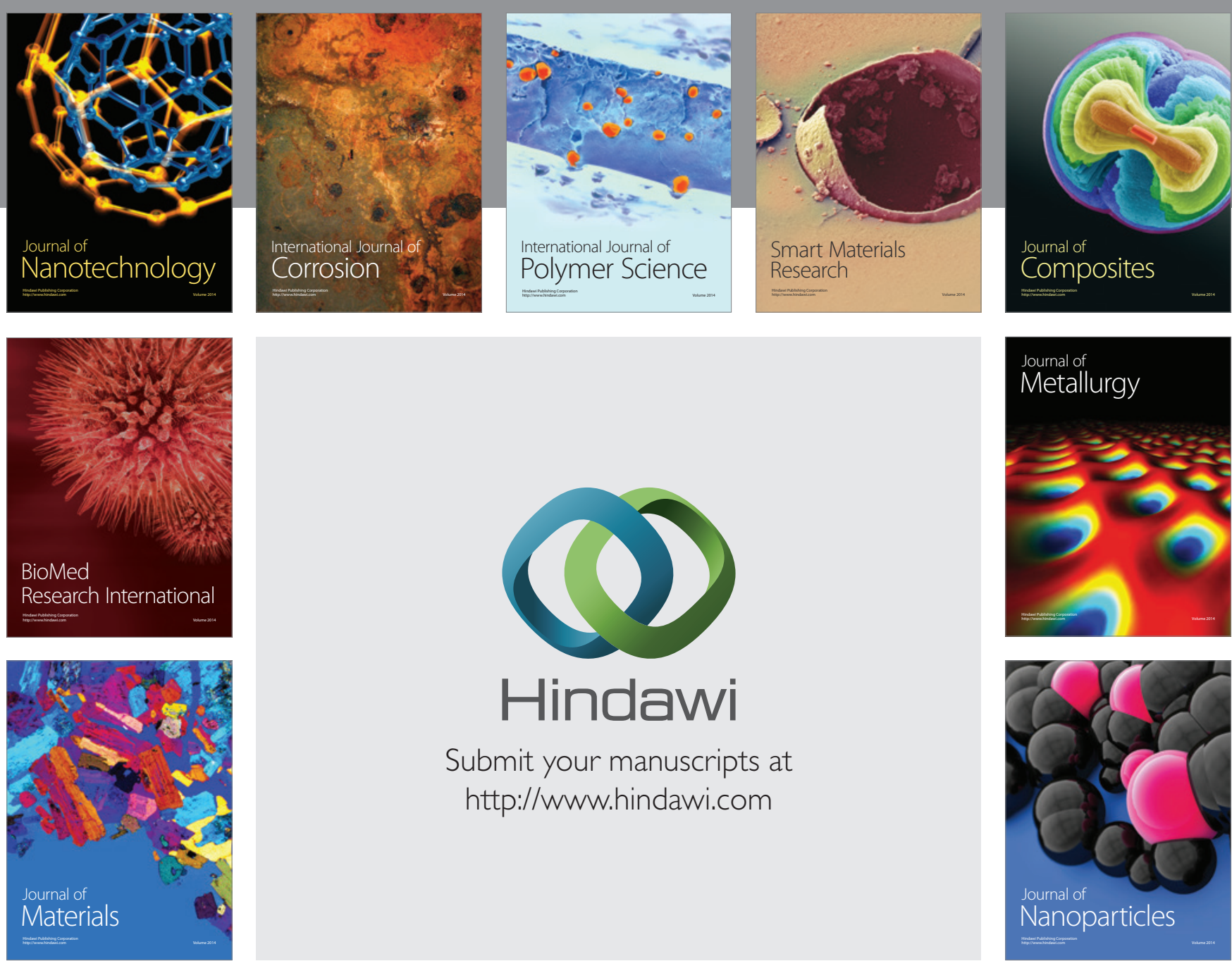

\section{Hindawi}

Submit your manuscripts at

http://www.hindawi.com

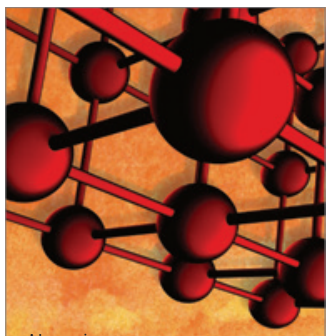

Materials Science and Engineering
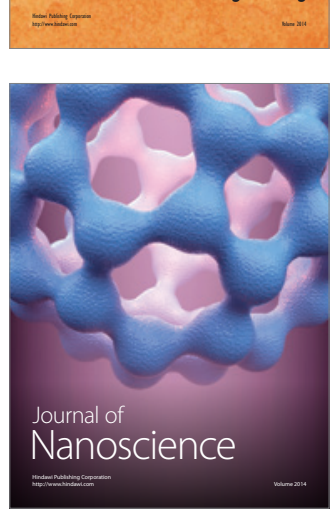
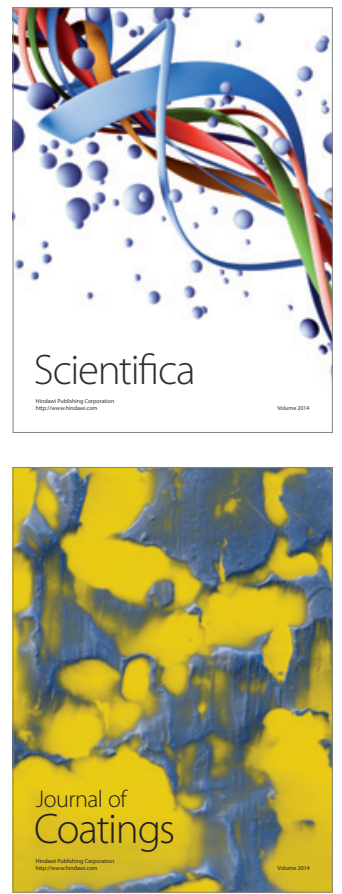
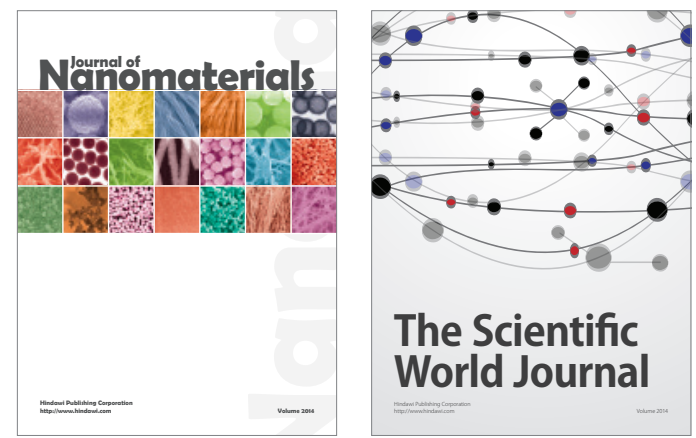

The Scientific World Journal
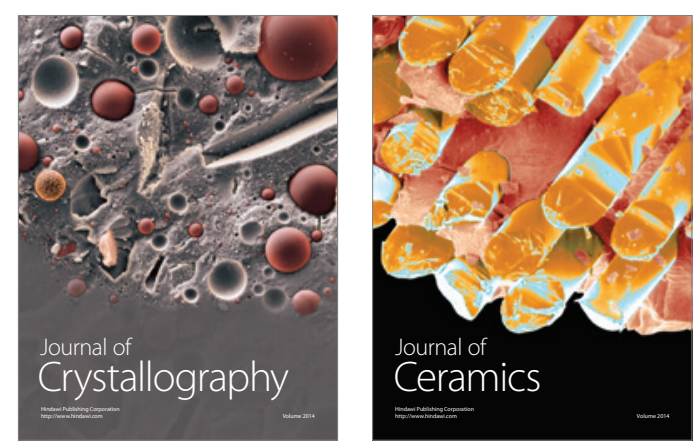
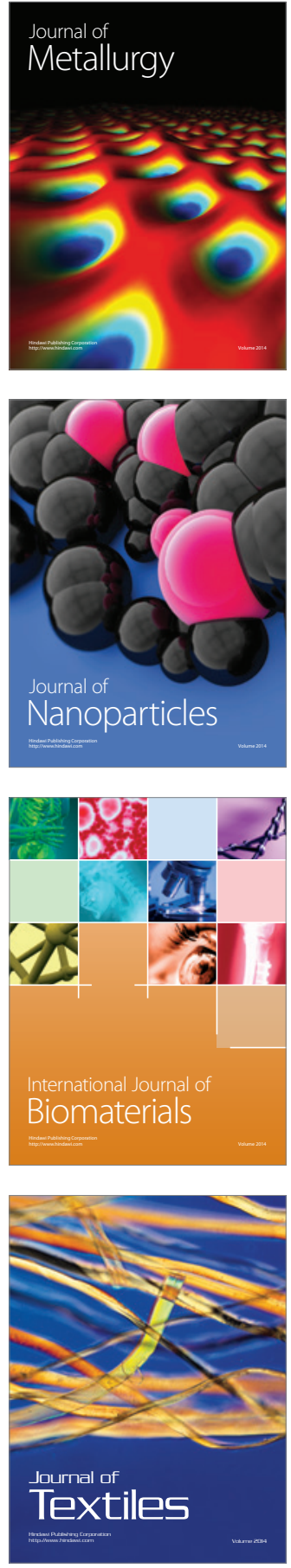